\title{
COVID-19 in pediatric cancer: where are the brain tumors?
}

\author{
Rebecca Ronsley ${ }^{1}$ and Eric Bouffet ${ }^{2}$ \\ ${ }^{1}$ University of British Columbia Faculty of Medicine \\ ${ }^{2}$ Hospital for Sick Children
}

April 8, 2021

\begin{abstract}
Treatment of pediatric oncology patients generally results in significant immunosuppression and when the COVID-19 pandemic arose, there was concern among pediatric oncologists about the implications of this virus. We reviewed the literature and describe all pediatric oncology patients with COVID-19 reported worldwide. Within this review, it is striking that CNS tumors are reported at low numbers (27/466 pediatric oncology patients with COVID-19). This may be related to decreased inpatient care when compared to other pediatric cancers. Additional work is needed to understand the risk of infection in this population and gain insight into the effect on delivery of oncology care.
\end{abstract}

\section{Hosted file}

Brain Tumors and COVID-19 Brief Report FINAL.pdf available at https://authorea.com/users/ 406645/articles/517238-covid-19-in-pediatric-cancer-where-are-the-brain-tumors 